Original Research Paper

\title{
Optimization of Egg Tofu Formulations Containing Carrageenan, Gum Arabic and Corn Starch by Descriptive Sensory Analysis
}

\author{
${ }^{1,2}$ Maizura Murad, ${ }^{1}$ Aminah Abdullah and ${ }^{1}$ Wan Aida Wan Mustapha \\ ${ }^{I}$ School of Chemical Sciences and Food Technology, Faculty of Science and Technology, \\ Universiti Kebangsaan Malaysia, 43600 UKM Bangi, Selangor, Malaysia \\ ${ }^{2}$ School of Industrial Technology, Universiti Sains Malaysia, 11800 Penang, Malaysia
}

Article history

Received: 06-12-2014

Revised: 03-01-2015

Accepted: 27-01-2015

Corresponding Author:

Aminah Abdullah

School of Chemical Sciences and Food Technology, Faculty of Science and Technology, Universiti Kebangsaan Malaysia, 43600 UKM Bangi, Selangor, Malaysia

Email: aminahsensory@ukm.edu.my

\begin{abstract}
The objectives of this study was to determine the effects of carrageenan, gum Arabic and corn starch on the sensory characteristics of egg tofu and to optimize egg tofu formulations using Response Surface Methodology (RSM). A Central Composite Design (CCD) with three factors was used to study the effects of carrageenan $(0.1-0.2 \%)$, gum Arabic (0.1-1.0\%) and corn starch (1.5-2.5\%) on the sensory characteristics of egg tofu. Eight trained panelists performed quantitative descriptive analysis. Analysis of Variance (ANOVA) showed that several of the response variables (egg aroma, starchiness, cohesiveness, astringency and aftertaste) were significantly different $(\mathrm{p}<0.05)$ and that the coefficients of determination $\left(\mathrm{R}^{2}\right)$ were in the range of $0.77-0.96$. Based on the superimposed plot to determine the overlay region for sensory attributes, the formulation of egg tofu with desired sensory quality was obtained by incorporating $0.12 \%$ carrageenan, $0.61 \%$ gum Arabic and $2.00 \%$ corn starch. The best sensory performances were set as a goal for each response and the results showed that the optimum predicted response values obtained for egg aroma, starchiness, cohesiveness, astringency and aftertaste were $62,88,37,34$ and $60 \mathrm{~mm}$ respectively.
\end{abstract}

Keywords: Egg Tofu, Descriptive Sensory Analysis, Optimization, Respond Surface Methodology (RSM), Central Composite Design (CCD)

\section{Introduction}

There are various types of soy tofu available in the market such as dry tofu, firm tofu, soft tofu, silken tofu and filled (packed) tofu. Soy tofu has been consumed in Asia for thousands of years and it is known as traditional foods. Nowadays, egg tofu is getting popular among Asians. Egg tofu, which is also known as "Japanese tofu", is a savory tofu that is yellowish in color and possesses a strong egg aroma. Egg tofu is formed by the gelling process of whole eggs and soymilk (or seasoning) in the presence of a coagulant, such as Glucono-Delta-Lactone (GDL). The effect of hydrocolloids on the physico-chemical and sensory properties of soy tofu have been studied (Karim et al., 1999; Chang et al., 2003). However, there is less literature available on the incorporation of hydrocolloids in egg tofu. Therefore, it is desirable to determine the effects of the addition of carrageenan, gum Arabic and corn starch on the sensory characteristics of egg tofu.
A previous study has shown that the soy tofu gel becomes more stable with synergistic effect between carrageenan and soy protein (Baeza et al., 2002) and that $0.2 \%$ carrageenan enhances the water holding capacity of soy tofu (Karim et al., 1999). Gum Arabic is a complex branched hetero polyelectrolyte (Goycoolea et al., 1995). An addition of gum Arabic in an orange beverage formulation can trap the volatile components (Mirhosseinia et al., 2008). Starch is used in food applications because it is easy to cook at high concentrations and it can control moisture migration (Sajilata and Singhal, 2005). Moreover, starch can trap the flavor of food and reduce the astringent taste of phenolic acid (Naknean and Meenune, 2010; Troszynska et al., 2010). The astringent taste of egg tofu is due to the phenolic acids and isoflavones compounds in soymilk (Labbe et al., 2006). In the present study increased amount of cornstarch had significantly $(p<0.05)$ reduce the astringent taste of egg tofu. However, the utilization of starch is limited due to its 
cohesive texture, heat sensitivity and opacity appearance in food (Sajilata and Singhal, 2005).

Sensory characteristics of food products are crucial for providing products with desired sensory properties. Sensory descriptive analysis can specify the intensity of sensory attributes in food products (Cartier et al., 2006). Several studies (Dutcosky et al., 2006; Gan et al., 2007; Brannan, 2009; Monaco et al., 2010; Yoon et al., 2011) have analyzed food properties using sensory descriptive analysis. The application of descriptive analysis requires extensive training to make sure that the panel agrees with the terminology and rating scales, so that the terms and scales can be used consistently to discriminate the samples.

Response Surface Methodology (RSM) is an effective statistical technique in optimizing product formulations because it can minimize the number of experiments and it is less time consuming. It consists of a statistical procedure that can be used to determine the relationships between the ingredients (independent variables or factors) and the response (dependent variables) (Castro et al., 2003). The optimization process is achieved by employing regression for the construction of empirical models that describe the product characteristics. Several studies have successfully used RSM to optimize ingredients in chestnut-based chips (Monaco et al., 2010), orange beverage emulsion (Mirhosseinia et al., 2008), pistachio nut roasting process (Kahyaoglu, 2008), traditional baked cassava cake (Gan et al., 2007), chocolate-flavored peanut-soy beverage (Deshpande et al., 2008), tropical mixed fruit jam (Abdullah and Cheng, 2001) and peanut milk-based whipped topping (Aminah et al., 1993). The objectives of this study was to determine the effects of carrageenan, gum Arabic and corn starch on the sensory characteristics of egg tofu using sensory descriptive analysis and to optimize the best formulation of egg tofu leading to the best sensory performance using RSM.

\section{Materials and Methods}

\section{Materials}

Yellow soybeans (Canada), Glucono-Delta-Lacton (GDL) and corn starch were obtained from Yummy's Bakery Sdn. Bhd. (Selangor, Malaysia). Egg (Gred A) obtained from Giant hypermarket (Selangor, Malaysia), Carrageenan powderwas obtained from Omigel Sdn. Bhd. (Semporna, Sabah, Malaysia) and gum Arabic was obtained from Manna Fiber Co Sdn. Bhd. (Selangor, Malaysia).

\section{Experimental Design}

Response Surface Methodology (RSM) was applied to determine the experimental design and the formulations of egg tofu were selected according to a Central Composite Design (CCD). Three independent variables, including carrageenan $\left(\mathrm{X}_{1}\right)$, gum Arabic $\left(\mathrm{X}_{2}\right)$ and corn starch $\left(\mathrm{X}_{3}\right)$, were tested against the following 14 response variables: Yellow color, egg aroma, soymilk aroma, egg taste, soy taste, starchiness, saltiness, cohesiveness, oiliness, firmness, surface roughness, astringency, aftertaste and overall acceptability. Coded variables and actual percentages of the ingredients used in the egg tofu formulations are shown in Table 1. Each independent variable had five coded levels $(-1,682,-1,0,1$ and 1.682) and 19 formulations including five replicated central points were required for the three variables.

\section{Preparation of Egg Tofu}

Soybean seeds were soaked in water, rinsed, ground with water at a bean: Water ratio of 1:3 and filtered with muslin cloth. The slurry was cooked at $100^{\circ} \mathrm{C}$ for $15 \mathrm{~min}$. Egg tofu was prepared from a mixture of soymilk and fresh egg $(2: 1)$. Initially, carrageenan $(0.1-0.2 \% \mathrm{w} / \mathrm{w})$, gum Arabic (0.1-1.0\% w/w) and corn starch (1.5-2.5\% $\mathrm{w} / \mathrm{w})$ were added to the soymilk, which was then heated to a temperature of $80^{\circ} \mathrm{C}$ with continuous stirring until these components were completely dissolved. The mixture was then cooled to $40^{\circ} \mathrm{C}$ followed by the addition of a filtered fresh whole egg and Glucono-Delta-Lactone (GDL) (0.4\% $\mathrm{w} / \mathrm{w})$ and the mixture was mixed well. The mixture was poured into a plastic container $(5.5 \mathrm{~cm}$ diameter and 4.0 $\mathrm{cm}$ high) and it was steamed at $90^{\circ} \mathrm{C}$ for $20 \mathrm{~min}$. Samples were cooled to room temperature and stored at $4{ }^{\circ} \mathrm{C}$ prior to being used for sensory evaluation.

\section{Descriptive Sensory Analysis}

Eight panelists ( 1 male and 7 female) ages 24-39 year old who were students and staffs of Faculty of Science and Technology at Universiti Kebangsaan Malaysia, participated in the sensory evaluation test. The panelists were selected based on previous experience in descriptive sensory analysis, availability, motivated to participate and consumption of egg tofu. Panelists were trained over 12, $2 \mathrm{~h}$ per session, 2 times per week, for 3 weeks. In the training sessions, the Spectrum ${ }^{\mathrm{TM}}$ Descriptive Analysis Method (Meilgaard et al., 2006) was used to train panel and evaluate samples. Panelists were asked to generate terminology for both the commercial egg tofu and experimental samples in terms of sensory attributes (color, aroma, taste and texture) and fourteen sensory attributes were generated as shown in Table 2. The reference standard for each attributes and intensity selected were based on the Spectrum Intensity Scales for Descriptive Analysis (Meilgaard et al., 2006) (Table 2). The intensity for each reference was vertically marked on a $150 \mathrm{~mm}$ unstructured line scale before rating the actual sample intensity according to the specific sensory attributes. The panelists then familiarized themselves with the references until they can consistently identify the intensity rate for each sensory attributes prior to actual sample evaluation. 
Table 1. Coded and actual percentages of independent variables in egg tofu formulations and response variables

\begin{tabular}{|c|c|c|c|c|c|c|c|c|c|c|c|}
\hline \multirow[b]{2}{*}{$\begin{array}{l}\text { Formula } \\
\text { tion no. }\end{array}$} & \multicolumn{3}{|l|}{ Coded } & \multicolumn{3}{|l|}{ Percent (\%) } & \multicolumn{5}{|c|}{ Mean sensory score $^{\mathrm{a}}$} \\
\hline & $X_{1}$ & $\mathrm{X}_{2}$ & $\mathrm{X}_{3}$ & Carrageenan & $\begin{array}{l}\text { Gum } \\
\text { Arabic }\end{array}$ & $\begin{array}{l}\text { Corn } \\
\text { Starch }\end{array}$ & $\begin{array}{l}\text { Egg aroma } \\
\left(\mathrm{Y}_{1}\right)\end{array}$ & $\begin{array}{l}\text { Starchiness } \\
\left(\mathrm{Y}_{2}\right)\end{array}$ & $\begin{array}{l}\text { Cohesiveness } \\
\left(\mathrm{Y}_{3}\right)\end{array}$ & $\begin{array}{l}\text { Astringency } \\
\left(\mathrm{Y}_{4}\right)\end{array}$ & $\begin{array}{l}\text { Aftertaste } \\
\left(\mathrm{Y}_{5}\right)\end{array}$ \\
\hline 1 & $-1-000$ & $-1-000$ & $-1-000$ & 0.12 & 0.28 & 1.7 & 42 & 70 & 18 & 25 & 72 \\
\hline 2 & $1-000$ & $-1-000$ & $-1-000$ & 0.18 & 0.28 & 1.7 & 86 & 86 & 66 & 25 & 56 \\
\hline 3 & $-1-000$ & $1-000$ & $-1-000$ & 0.12 & 0.82 & 1.7 & 99 & 69 & 18 & 36 & 72 \\
\hline 4 & $1-000$ & $1-000$ & $-1-000$ & 0.18 & 0.82 & 1.7 & 82 & 88 & 37 & 23 & 94 \\
\hline 5 & $-1-000$ & $-1-000$ & $1-000$ & 0.12 & 0.28 & 2.3 & 69 & 94 & 62 & 16 & 83 \\
\hline 6 & $1-000$ & $-1-000$ & $1-000$ & 0.18 & 0.28 & 2.3 & 78 & 99 & 68 & 32 & 91 \\
\hline 7 & $-1-000$ & $1-000$ & $1-000$ & 0.12 & 0.82 & 2.3 & 79 & 101 & 65 & 34 & 73 \\
\hline 8 & $1-000$ & $1-000$ & $1-000$ & 0.18 & 0.82 & 2.3 & 69 & 117 & 57 & 35 & 81 \\
\hline 9 & -1.682 & $0-000$ & $0-000$ & 0.10 & 0.55 & 2.0 & 66 & 101 & 41 & 25 & 53 \\
\hline 10 & 1.682 & $0-000$ & $0-000$ & 0.20 & 0.55 & 2.0 & 71 & 110 & 66 & 41 & 58 \\
\hline 11 & $0-000$ & -1.682 & $0-000$ & 0.15 & 0.10 & 2.0 & 56 & 86 & 62 & 29 & 81 \\
\hline 12 & $0-000$ & 1.682 & $0-000$ & 0.15 & 1.00 & 2.0 & 87 & 88 & 29 & 34 & 86 \\
\hline 13 & $0-000$ & $0-000$ & -1.682 & 0.15 & 0.55 & 1.5 & 62 & 74 & 31 & 31 & 86 \\
\hline 14 & $0-000$ & $0-000$ & 1.682 & 0.15 & 0.55 & 2.5 & 54 & 104 & 63 & 18 & 83 \\
\hline 15 & $0-000$ & $0-000$ & $0-000$ & 0.15 & 0.55 & 2.0 & 58 & 85 & 42 & 41 & 61 \\
\hline 16 & $0-000$ & $0-000$ & $0-000$ & 0.15 & 0.55 & 2.0 & 57 & 89 & 44 & 34 & 62 \\
\hline 17 & $0-000$ & $0-000$ & $0-000$ & 0.15 & 0.55 & 2.0 & 45 & 86 & 41 & 37 & 65 \\
\hline 18 & $0-000$ & $0-000$ & $0-000$ & 0.15 & 0.55 & 2.0 & 48 & 88 & 37 & 33 & 70 \\
\hline 19 & $0-000$ & $0-000$ & $0-000$ & 0.15 & 0.55 & 2.0 & 57 & 91 & 42 & 36 & 69 \\
\hline
\end{tabular}

${ }^{\mathrm{a}}$ Mean sensory score of eight panelists in two replications using a $150 \mathrm{~mm}$ rating scale.

Table 2. Descriptions, references and intensity for sensory attributes

\begin{tabular}{|c|c|c|c|}
\hline Attributes & Descriptions & References & Intensity (mm) \\
\hline \multicolumn{4}{|l|}{ Appearance } \\
\hline Yellow color & Intensity of the sample color from whitish to yellowish & Color paint (creamy white) & 45 \\
\hline \multicolumn{4}{|c|}{ (2) } \\
\hline Egg & Aromatics of hardboiled egg & Hardboiled egg & 135 \\
\hline Soymilk & Aromatics of cooked soymilk & Cooked soy milk, soybean: water $(1: 3)$ & 90 \\
\hline \multicolumn{4}{|c|}{ e } \\
\hline Firmness & Force required to bite through with incisors & ${ }^{\mathrm{a}}$ Frankfurter (Tesco Smoke Frankfurter) & 50 \\
\hline Surface roughness & Degree to which the sample lacks bumps, lumps or air bubbles & ${ }^{\mathrm{a}}$ Frankfurter (Tesco Smoke Frankfurter) & 20 \\
\hline Cohesiveness & Degree to which sample deforms rather than cracks or breaks & ${ }^{a}$ Dried fruit (raisins Sun-Maid) & 10 \\
\hline Oiliness in mastication & Degree to which sample feels oily on any mouth surface & ${ }^{a}$ Potato chips (Master Potato) & 15 \\
\hline \multicolumn{4}{|c|}{ Taste } \\
\hline Egg & Taste of hardboiled egg & ${ }^{\mathrm{a}}$ Hardboiled egg & 120 \\
\hline Soy & Taste of cook soy milk & Cooked soy milk, soybean: water $(1: 3)$ & 130 \\
\hline Starchiness & Taste of starch of a particular grain source & Gelatinized corn starch, starch: water $(1: 120)$ & 135 \\
\hline Saltiness & Basic taste sensation elicited by salts & ${ }^{\mathrm{a}} 0.2$ and $0.5 \% \mathrm{NaCl}$ solution & 25,85 \\
\hline Astringency & Puckering or tingling sensation elicited by tea & ${ }^{\mathrm{a}} 1$ tea bag soak in 1 cup hot water for $3 \mathrm{~min}$ & 70 \\
\hline \multirow[t]{3}{*}{ Aftertaste } & A mixture taste of astringent, sour and stickiness feel & Commercial egg tofu & \\
\hline & inside the whole mouth detected & (Red hen brand Wai Food Industry) & \\
\hline & after the egg tofu had been swallows & & 77 \\
\hline
\end{tabular}

adapted from (Meilgaard et al., 2006). Reference intensities were calculated as the mean rating of the group of eight panelists using a 150 mm unstructured line scale where $0=$ none and $150=$ very high intensity

For the sensory evaluation, samples of egg tofu (5.5 $\mathrm{cm}$ diameter $\times 2.0 \mathrm{~cm}$ high) were taken from the refrigerator $\left(4^{\circ} \mathrm{C}\right)$ and deep-fat fried using cooking palm oil obtained from Sime Darby Food and Beverages Marketing Sdn. Bhd. (Selangor, Malaysia) at $180^{\circ} \mathrm{C}$ for 3 min. Fried samples $(5.2 \mathrm{~cm}$ diameter $\times 1.8 \mathrm{~cm}$ high) were then cooled to room temperature before they were cut into three portions. Samples were served on white translucent plates, coded with 3-digit random numbers. References for each sensory attributes were given to the panelists. Distilled water was provided for the panelist to rinse their palates between samples. Panelists then test the samples in individual booth in the sensory room.
Four or five samples were evaluated in a random order during each of the 4 sessions. Each sample was evaluated in duplicate on separate testing days.

\section{Statistical Analysis}

A central composite design was used and statistical analyses of the data for egg tofu containing carrageenan, gum Arabic and corn starch were performed using the Design Expert software package (version 6.0.10; State-Ease Inc., Minneapolis, MN, USA). The three-dimensional response surface showed the effects of independent variables (carrageenan, gum Arabic and corn starch) on the response variables 
(sensory attributes) using the regression polynomial equation. The following equation was obtained using RSM for predicting the response variables:

$$
\begin{aligned}
& Y \mathrm{i}=\beta_{0}+\beta_{1} X_{1}+\beta_{2} X_{2}+\beta_{3} X_{3}+\beta_{11} X_{1}^{2} \\
& +\beta_{22} X_{2}^{2}+\beta_{33} X_{3}^{2}+\beta_{12} X_{1} X_{2}+\beta_{13} X_{1} X_{3}+\beta_{23} X_{2} X_{3}
\end{aligned}
$$

Where:

$\mathrm{Y} i=$ The predicted response;

$\beta_{0} \quad=$ The value of the fixed response at the central point of the experiment;

$\beta_{1,} \beta_{2}$ and $\beta_{3} \quad=$ The regression coefficients for linear effect terms;

$\beta_{11}, \beta_{22}$ and $\beta_{33}=$ The regression coefficients for quadratic effect terms; and

$\beta_{12}, \beta_{13}$ and $\beta_{23}=$ The regression coefficients for the interaction effect terms.

The statistical analysis of the models was evaluated with analysis of variance (ANOVA). The criteria of the model used to generate the response surface plot should be significant $(p<0.05)$. The lack-of-fit must not be significant $(p>0.05)$ and a coefficient of determination $\left(\mathrm{R}^{2}\right)$ greater than 0.70 .

\section{Optimization Procedure and Verification of Models}

Numerical optimization was performed to determine the optimum level of independent variables (carrageenan, gum Arabic and corn starch) that produced desirable response variables (sensory attributes) of egg tofu. The contour plots for the response variables were created and they were superimposed to obtain the optimum formulation. The optimum formulation was selected and it was used to calculate the predicted values of response variables using the prediction equations. For verification, the predicted value of the response variables was statistically compared to the experimental value, which was the mean of three replicates.

\section{Results}

Based on visual observation, all produced egg tofu samples were light yellow. Different amounts of carrageenan, gum Arabic and corn starch added to the egg tofu significantly $(\mathrm{p}<0.05)$ affected five sensory attributes (egg aroma, starchiness, cohesiveness, astringency and aftertaste) based on the response quadratic model. Table 3 shows the predicted equation for each sensory attribute. Statistical analysis suggested that the model was adequate and had no significant lack-of-fit. Moreover, the model had a coefficient of determination $\left(\mathrm{R}^{2}\right)$ greater than 0.70 , which was considered acceptable for sensory analysis (Abdullah et al., 1993) indicating that the variability of all responses was well explained by the models.
However, no significant differences $(p>0.05)$ were observed in the other sensory attributes (yellow color, oiliness, soymilk aroma, firmness, surface roughness, soy taste, egg taste and saltiness). This can be due to the amount of carrageenan, gum Arabic and corn starch used in egg tofu formulations were not high enough to have a significant effects on these attributes.

\section{Sensory Attributes of Egg Tofu}

The sensory scores obtained for the egg aroma from 15 for mulations of egg tofu was in the range of 42 to 99 $\mathrm{mm}$ (Table 1). The effect of carrageenan, gum Arabic and corn starch on the egg aroma can be visualized by the response surface plot shown in Fig. 1. An increased amount of gum Arabic caused an increased egg aroma (Fig. 1b), as its linear effect was positive at $p<0.05$. In addition, an increased amount of gum Arabic or carrageenan showed positive quadratic effect $(p<0.05)$ on the egg aroma of egg tofu (Fig. 1a).

The sensory score range obtained for starchiness attribute of egg tofu containing carrageenan, gum Arabic and corn starch was 69 to $117 \mathrm{~mm}$ (Table 1). The effect of carrageenan, gum Arabic and corn starch on the starchiness can be seen by the response surface plot shown in Fig. 2. An increased amount of corn starch showed a positive linear effect with the starchiness of egg tofu (Fig. 2b) and the positive quadratic effect of carrageenan on the starchiness of egg tofu is shown in Fig. $2 \mathrm{a}$.

Table 1 shows the mean sensory score for the cohesiveness, which was in the range of 18 to $68 \mathrm{~mm}$. Table 3 clearly shows that cohesiveness was significantly $(p<0.05)$ influenced by the following effects: Linear effect of carrageenan, gum Arabic and corn starch; quadratic effect of carrageenan; and interaction effects between carrageenan and gum Arabic and between carrageenan and corn starch. Figure 3 shows the effect of carrageenan, gum Arabic and corn starch on the cohesiveness of egg tofu through the response surface plot. An increased amount of carrageenan or corn starch resulted in higher cohesiveness of egg tofu (Fig. 3c).

The range of sensory scores for astringency attributes was 16 to $41 \mathrm{~mm}$ (Table 1). The response surface plot shows the effect of carrageenan, gum Arabic and corn starch on the astringent properties of egg tofu (Fig. 4). An increased amount of corn starch shows a negative quadratic effect on the intensity of the astringency of egg tofu (Fig. $4 \mathrm{~b}$ and $4 \mathrm{c}$ ).

The range of sensory scores for aftertaste attribute was 53 to $94 \mathrm{~mm}$ (Table 1). The effect of carrageenan, gum Arabic and corn starch on the aftertaste properties of egg tofu is shown in the response surface plot (Fig. 5). An increased amount of gum Arabic or corn starch showed a positive quadratic effect on aftertaste of egg tofu (Fig. 5b). 
Table 3. Predicted regression equation coefficient in actual terms for sensory attributes

\begin{tabular}{|c|c|c|}
\hline Attribute & Equation & $\mathrm{R}^{2}$ value \\
\hline \multirow[t]{2}{*}{ Egg aroma } & $\begin{array}{l}\mathrm{Y}_{1}=100.52-885.38 \mathrm{X}_{1}+256.47 \mathrm{X}_{2}{ }^{*}-60.13 \mathrm{X}_{3}+8198.68 \mathrm{X}_{1}^{2^{*}}+117.88 \mathrm{X}_{2}^{2^{*}}+39.99 \mathrm{X}_{3}{ }^{2}-1258.26 \\
\mathrm{X}_{1} \mathrm{X}_{2}{ }^{*}-398.45 \mathrm{X}_{1} \mathrm{X}_{3}-84.18 \mathrm{X}_{2} \mathrm{X}_{3} \\
\text { Model (Prob }>\mathrm{F})=0.0073\end{array}$ & \\
\hline & Lack of fit $=0.1590$ & 0.85 \\
\hline \multirow[t]{2}{*}{ Starchiness } & $\begin{array}{l}Y_{2}=107.33-1373.62 X_{1}^{*}-86.66 X_{2}+55.90 X_{3}^{*}+6212.34 X_{1}^{2^{*}}-14.97 X_{2}^{2}-2.38 X_{3}^{2}+208.20 \\
X_{1} X_{2}-215.67 X_{1} X_{3}+40.07 X_{2} X_{3} \\
\text { Model (Prob }>F)=0.0003\end{array}$ & \\
\hline & Lack of fit $=0.0673$ & 0.93 \\
\hline \multirow[t]{2}{*}{ Cohesiveness } & $\begin{array}{l}Y_{3}=-172.13+1124.10 \mathrm{X}_{1}^{*}-7.17 \mathrm{X}_{2}{ }^{*}+77.07 \mathrm{X}_{3}^{*}+4940.66 \mathrm{X}_{1}{ }^{2 *}+20.26 \mathrm{X}_{2}^{2}+23.41 \mathrm{X}_{3}^{2}-689.43 \\
\mathrm{X}_{1} \mathrm{X}_{2}{ }^{*}-981.11 \mathrm{X}_{1} \mathrm{X}_{3}{ }^{2}+31.62 \mathrm{X}_{2} \mathrm{X}_{3} \\
\text { Model (Prob }>\mathrm{F})=0.0001\end{array}$ & \\
\hline & Lack of fit $=0.0568$ & 0.96 \\
\hline \multirow[t]{2}{*}{ Astringency } & $\begin{array}{l}Y_{4}=-103.60-27.40 X_{1}+65.35 X_{2}+118.41 X_{3}-1680.57 X_{1}^{2}-26.30 X_{2}^{2}-48.81 X_{3}^{2^{*}}-428.19 \\
X_{1} X_{2}+420.73 X_{1} X_{3}+19.25 X_{2} X_{3} \\
\text { Model (Prob }>F)=0.0404\end{array}$ & \\
\hline & Lack of fit $=0.1335$ & 0.77 \\
\hline \multirow[t]{2}{*}{ Aftertaste } & $\begin{array}{l}Y_{5}=316.85+468.89 X_{1}-7.83 X_{2}-299.33 X_{3}-3253.11 X_{1}^{2}+97.80 X_{2}^{2^{*}}+84.23 \mathrm{X}_{3}^{2^{*}}+595.43 \\
X_{1} X_{2}+128.79 X_{1} X_{3}-90.91 X_{2} X_{3}^{*} \\
\text { Model (Prob }>F)=0.0049\end{array}$ & \\
\hline & Lack of fit $=0.1062$ & 0.87 \\
\hline
\end{tabular}

* Significant difference $(\mathrm{p}<0.05)$.

$\mathrm{X}_{1}=$ Carrageenan

$\mathrm{X}_{2}=$ Gum Arabic

$\mathrm{X}_{3}=$ Corn Starch
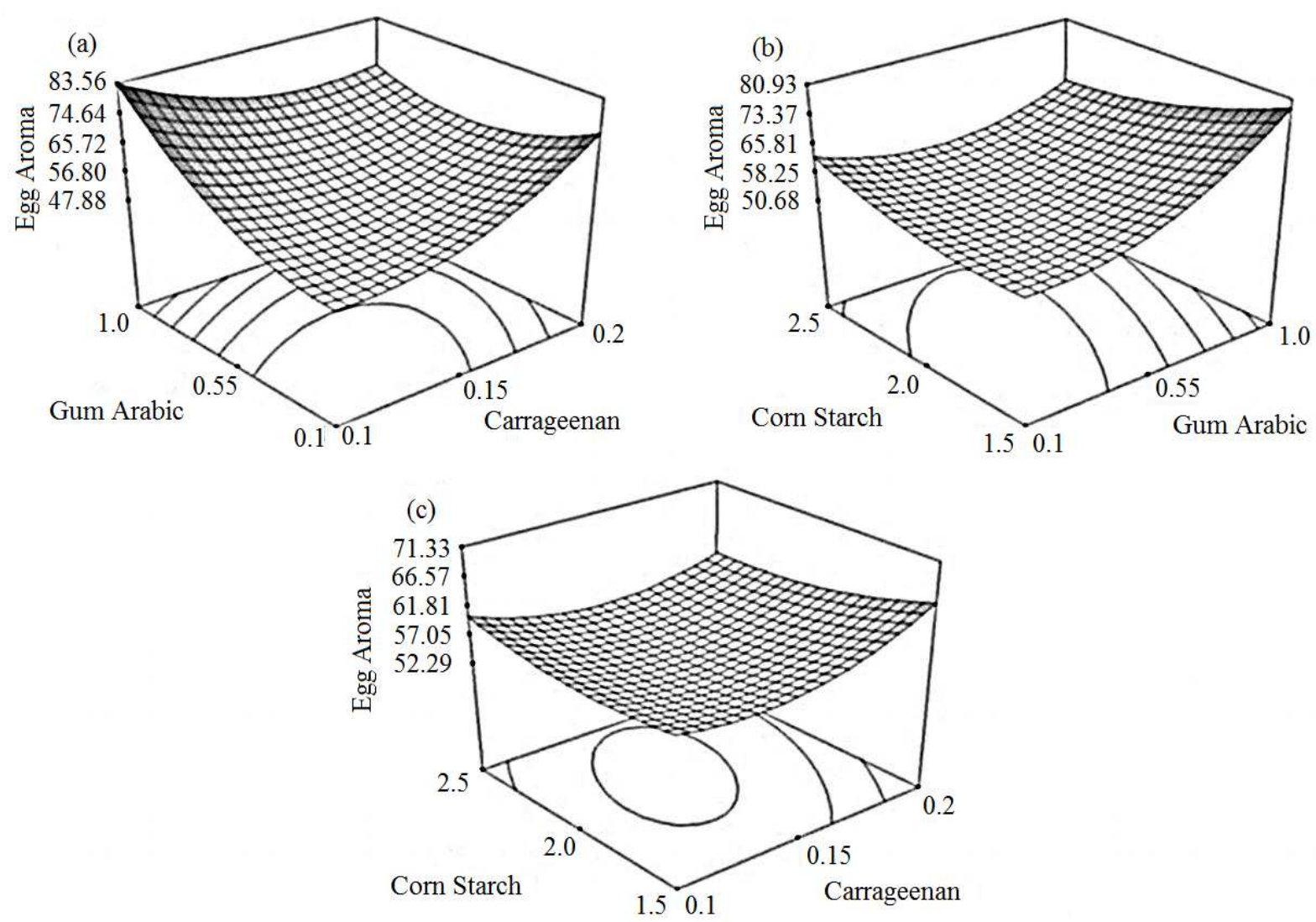

Fig. 1.Response surface for the effects of carrageenan, gum Arabic and corn starch on the egg aroma of egg tofu at (a) $2.00 \%$ corn starch, (b) $0.15 \%$ carrageenan and (c) $0.55 \%$ gum Arabic 

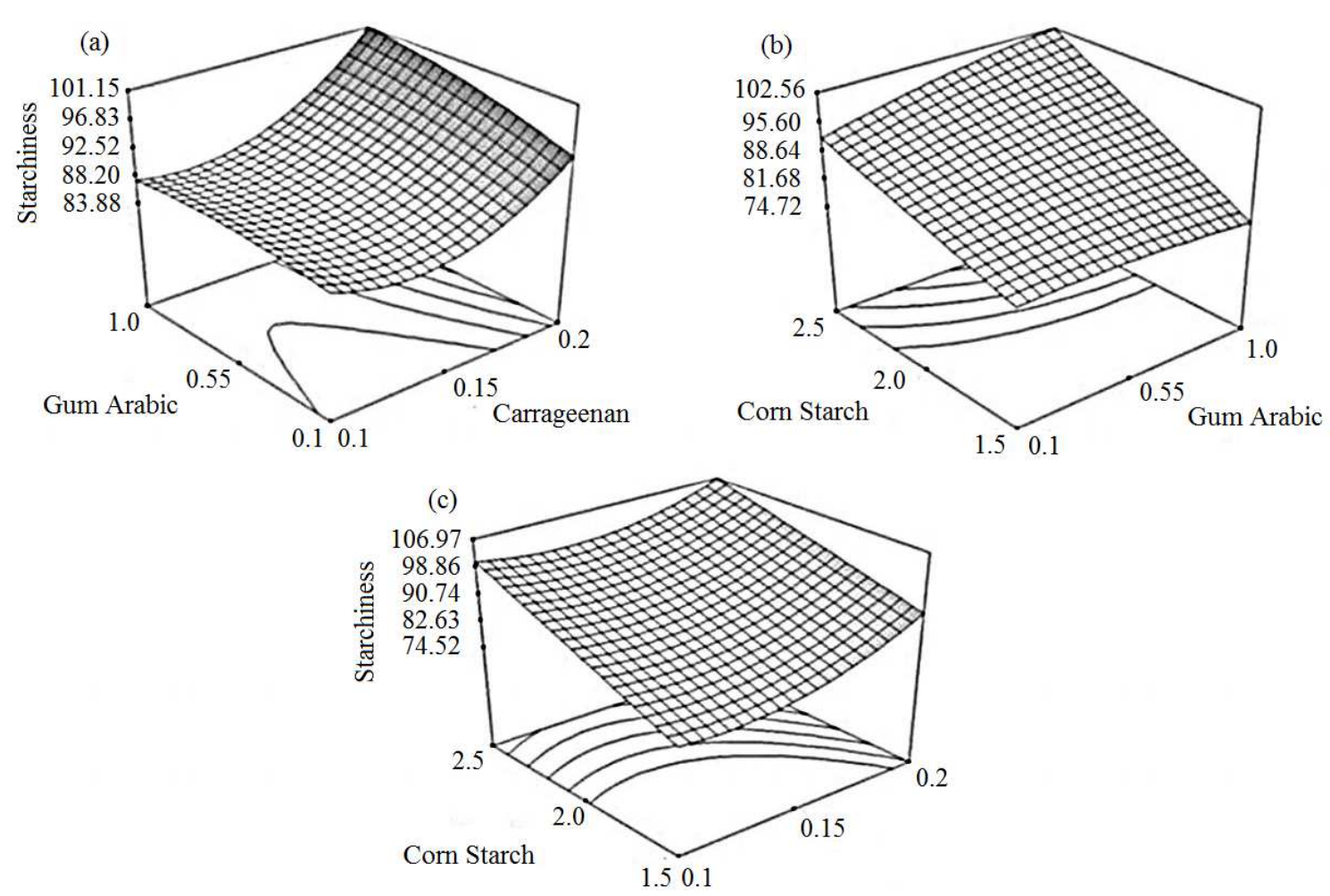

Fig. 2.Response surface for the effects of gum Arabic and carrageenan on the starchiness of egg tofu at (a) $2.00 \%$ corn starch, (b) $0.15 \%$ carrageenan and (c) $0.55 \%$ gum Arabic
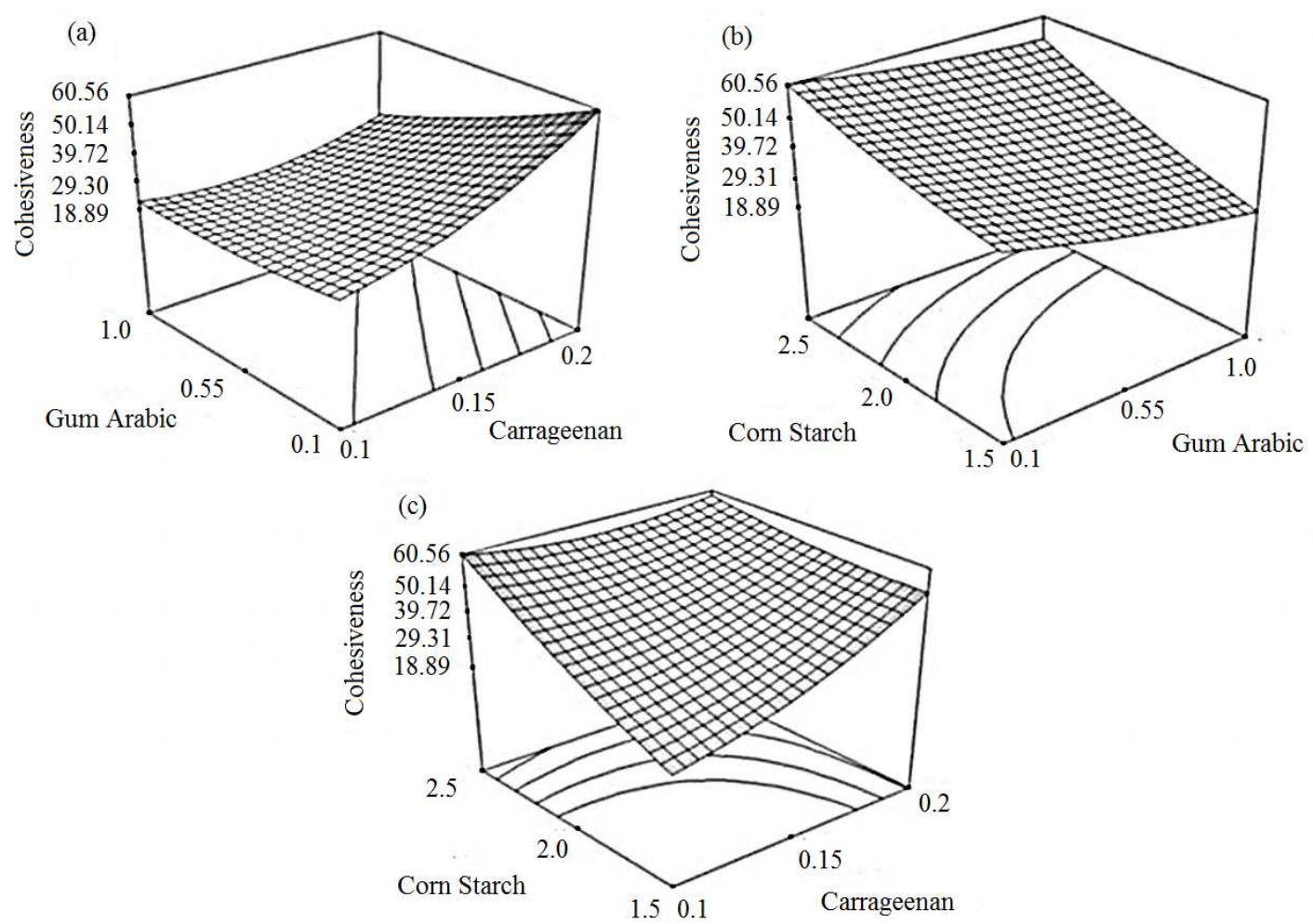

Fig. 3. Response surface for the effects of gum Arabic and carrageenan on the cohesiveness of egg tofu at (a) $2.00 \%$ corn starch, (b) $0.15 \%$ carrageenan and (c) $0.55 \%$ gum Arabic 

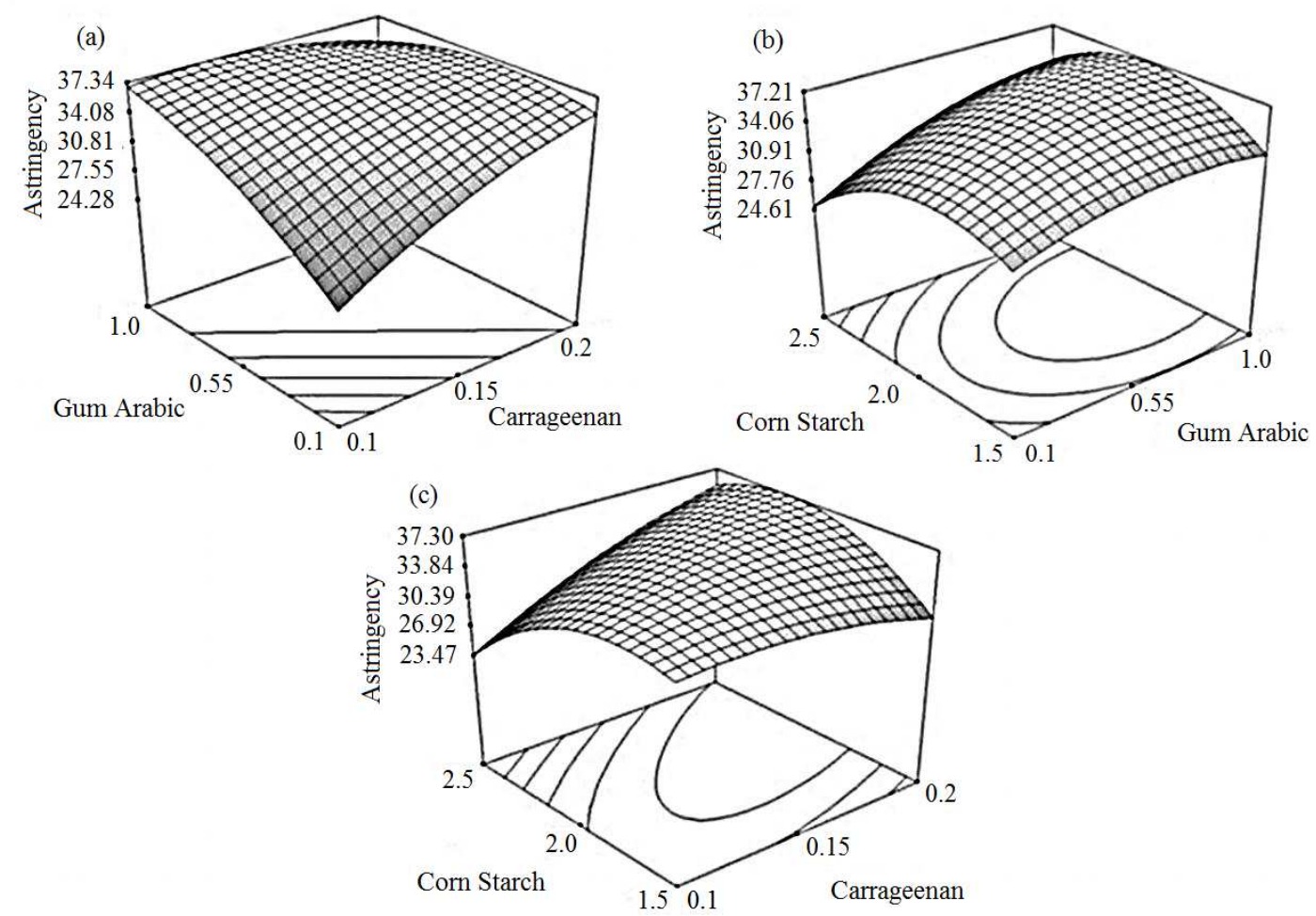

Fig. 4.Response surface for the effects of gum Arabic and carrageenan on the astringency of egg tofu at (a) $2.00 \%$ corn starch, (b) $0.15 \%$ carrageenan and (c) $0.55 \%$ gum Arabic
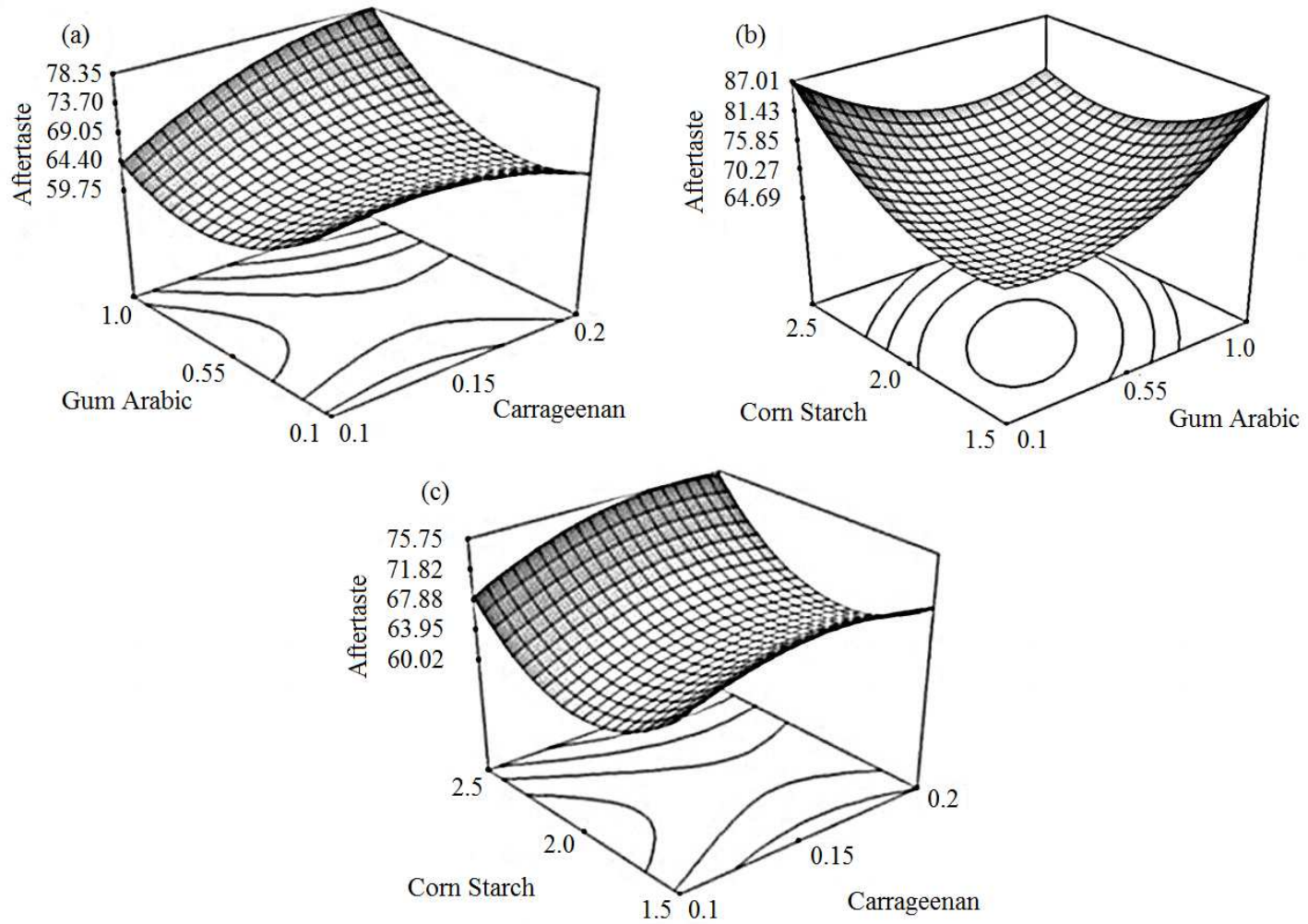

Fig. 5. Response surface for the effects of gum Arabic and carrageenan on the aftertaste of egg tofu at (a) $2.00 \%$ corn starch, (b) $0.15 \%$ carrageenan and (c) $0.55 \%$ gum Arabic 


\section{Optimization of the Egg Tofu Formulation and Verification of the Model}

The formulation of egg tofu was optimized to reduce the undesirable sensory properties such as aftertaste, astringency, starchiness and cohesiveness while inducing the egg aroma of egg tofu. Higher amount of corn starch had decreased $(p<0.05)$ the astringent taste of egg tofu, however, it had significantly $(\mathrm{p}<0.05)$ increased the aftertaste, starchiness and cohesiveness properties of egg tofu. Meanwhile, increased amount of gum Arabic or carrageenan was found to increase $(p<0.05)$ the egg aroma of egg tofu. Therefore, to obtain the optimum formulation of egg tofu, the region of the optimum condition was created by superimposing the contour plots of all the responses (aftertaste, astringency, starchiness, cohesiveness and egg aroma) in which the limits of each response have been determined (Fig. 6). The selection of any point within this region represented a combination of carrageenan, gum Arabic and corn starch that produced desirable sensory properties for each attribute of egg tofu.
Point A, which was selected in the superimposed region (Fig 6), indicated that the optimum formulation of egg tofu was $0.12 \%$ carrageenan, $0.61 \%$ gum Arabic and $2.00 \%$ corn starch. The predicted response and experimental values for egg aroma, starchiness, cohesiveness, astringency and aftertaste are shown in Table 4. For verification, the egg tofu with the optimum formulation was produced and analyzed. The experimental values for each response were statistically compared to those predicted by the equations of the model and the experimental and predicted values were not significantly $(\mathrm{p}>0.05)$ different.

Point B $(0.12 \%$ carrageenan, $0.64 \%$ gum Arabic and $1.80 \%$ corn starch) was outside of the optimum region and there were no significant $(p>0.05)$ differences observed between the predicted and experimental values (Table 4) for all response for this tofu formulation. Egg tofu formulations at point A (inside the region) and $\mathrm{B}$ (outside the region) had significantly $(p<0.05)$ different results for the starchiness, cohesiveness and aftertaste response variables.

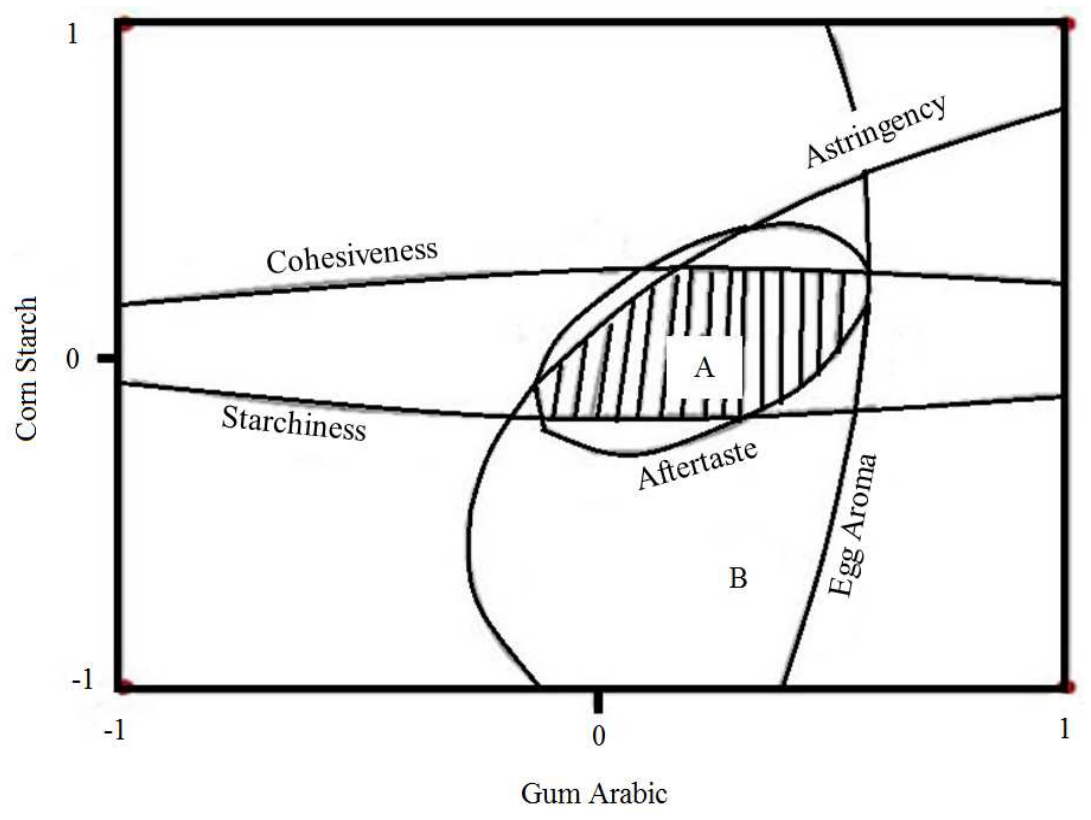

Fig. 6. Superimposed plots of the five response variables of egg tofu

Table 4. Predicted and experimental values for the response variables at point A and point $B$

\begin{tabular}{lllll}
\hline \multicolumn{5}{l}{ Table 4. Predicted and experimental values for the response variables at point A and point B } \\
& Point A & & Point B & \\
Response variables & Predicted values & Experimental values & Predicted values & Experimental values \\
\hline Egg aroma & $62^{\mathrm{a}}$ & $63 \pm 3^{\mathrm{a}}$ & $66^{\mathrm{a}}$ & $65 \pm 4^{\mathrm{a}}$ \\
Starchiness & $88^{\mathrm{a}}$ & $89 \pm 4^{\mathrm{a}}$ & $79^{\mathrm{b}}$ & $80 \pm 6^{\mathrm{b}}$ \\
Cohesiveness & $37^{\mathrm{a}}$ & $37 \pm 4^{\mathrm{a}}$ & $24^{\mathrm{b}}$ & $26 \pm 2^{\mathrm{b}}$ \\
Astringency & $34^{\mathrm{a}}$ & $34 \pm 2^{\mathrm{a}}$ & $35^{\mathrm{a}}$ & $34 \pm 2^{\mathrm{a}}$ \\
Aftertaste & $60^{\mathrm{c}}$ & $58 \pm 3^{\mathrm{bc}}$ & $64^{\mathrm{a}}$ & $63 \pm 4^{\mathrm{ab}}$ \\
\hline
\end{tabular}

Mean sensory score of eight panelists in three replications using a $150 \mathrm{~mm}$ rating scale \pm standard deviation. Values with a different superscript letter within each row are significantly different $(\mathrm{p}<0.05)$ 


\section{Discussion}

Aroma substances are volatile compounds that are perceived by the odor receptor sites of the smell organ. The presence of polysaccharides in food could affect the release and retention of the volatile compounds (Naknean and Meenune, 2010). The linear and quadratic terms of gum Arabic and quadratic term of carrageenan showed a significant $(p<0.05)$ positive effect which induced the egg aroma (Table 3). It is suggested that the presence of gum Arabic and carrageenan in egg tofu had trapped the volatile molecules by preventing the migration process of the molecules from the inside to the surface of food and thus retaining the egg aroma throughout the preparation of egg tofu. However, during the frying proses, the volatile molecules were released and contributed to the higher egg aroma. This is consistent with the results of (Terta et al., 2006), who reported that increased gum Arabic concentration had decreases the diffusion rate of aroma compounds through the interface of the solution. However, there was no change observed for egg aroma with increasing amounts of corn starch.

Starch is the most common form of carbohydrate in our diet. It is used in various food products as thickener and gelling agent (McWilliams, 1997). Generally, food containing starchform a thicken starch paste or a stiff gel and contributes to starchy taste. The linear, quadratic and interaction effect of carrageenan, gum Arabic and corn starch on the starchiness of egg tofu is presented in Table 3. The incorporation of corn starch and carrageenan in egg tofu formulation markedly affects the starchiness properties of egg tofu. Results showed that corn starch was the main contributor to the starchiness as evident by the significant $(p<0.05)$ positive linear effect on the starchiness properties of egg tofu. Carrageenan also contributed to the starchiness of egg tofu where the predicted regression equation coefficient shows a significant $(\mathrm{p}<0.05)$ positive quadratic effect. Gum Arabic is non-starch polysaccharides (Annison et al., 1995) and therefore, incorporated of gum Arabic did not significantly $(p>0.05)$ contribute to the starchiness of egg tofu.

Cohesiveness was measured by the degree of difficulty in breaking down the internal structure of egg tofu, which was varied with the amount of polysaccharides used. The linear term of carrageenan or corn starch had a significant $(\mathrm{p}<0.05)$ positive effect on cohesiveness. The aggregation and gelation behavior of these polysaccharides contributed to the changes of textural properties as similarly proposed by (Dickinson, 2003). Previous studies (Karim et al., 1999) have found that $0.2 \%$ carrageenan had result in the increase of cohesiveness of tofu. According to Venugopal (2008), the incorporation of protein in carrageenan gels increases the cohesiveness and reduces gel syneresis.
This could be due to the excluded volume effects that increased the concentration of the hydrocolloid and electrostatic interaction between protein and carrageenan in solution (Baeza et al., 2002). In addition, starch also contributed to the cohesiveness as similarly reported by (Sajilata and Sighal, 2005). On the other hand, an increased amount of gum Arabic have a negative linear effect $(p<0.05)$ on cohesiveness.

Astringency is a sensory attribute that is describe as a drying out, roughening and puckering mouth feel (Gawell et al., 2000). The intensity of astringency plays an important role towards acceptance of food products (Monteleone et al., 2004). The detection of astringency in egg tofu is due to the presence of phenolic acids and isoflavones compounds such as daidzein and genistein in soymilk (Lesschaeve and Nobel, 2005; Labbe et al., 2006). The quadratic term of corn starch showed a significant $(\mathrm{p}<0.05)$ negative effect on astringency of egg tofu (Tables 3). It indicates that, an increased amount of corn starch can effectively reduce astringency. Polysaccharides are well known for their ability to lower the intensity of taste and aroma when their concentration is above the coil overlap concentration (Troszynska et al., 2010). In this study, it seems that corn starch had reduced the intensity of astringency via binding the astringent compounds in the helical amylose through hydrophobic bonding as stated by (Boutboul et al., 2002). However, the presence of carrageenan and gum Arabic did not significantly $(p>0.05)$ affect the astringent properties of egg tofu.

Aftertaste is described as the taste intensity that is perceived immediately after a food product is removed from the mouth (Meilgaard et al., 2006). In this study, the resulting aftertaste after the egg tofu had been swallows were a mixture of astringent, sour and stickiness feel inside the whole mouth which are not preferred by the panelist.The astringency felt can be cause by fenolic acids and isoflavon component found in soy milk (Labbe et al., 2006), while the sour taste was caused by glocoronic acid that was produced by GDL. Table 3 shows a positive significant $(p<0.05)$ quadratic effect of gum Arabic or corn starch on the aftertaste of egg tofu. It shows that gum Arabic or corn starch had traped the astringent and sour taste in egg tofu and were released in mouth after the egg tofu had been swallows. The presence of carrageenan in egg tofu, however do not affect the aftertaste of egg tofu.

\section{Conclusion}

The application of a Central Composite Design (CCD) was useful in optimizing the formulations of egg tofu because it allowed the optimization of sensory properties when testing combinations of different amounts of carrageenan, gum Arabic and corn starch. Increased gum Arabic and carrageenan contents 
enhanced the egg aroma of egg tofu. The starchiness, cohesiveness and aftertaste properties of egg tofu were attributed mainly to corn starch. The overlap area with desired sensory attributes was generated and the optimum formulation of egg tofu contained $0.12 \%$ carrageenan, $0.61 \%$ gum Arabic and $2.00 \%$ corn starch. The experimental values were not significantly different $(\mathrm{p}>0.05)$ from the predicted value, thereby, indicating that the optimization equation obtained through CCD was valid and acceptable.

\section{Acknowledgement}

The researchers would like to express their gratitude to Universiti Kebangsaan Malaysia for their financial support (UKM-GUP grant-NBT-08-27-103 and UKM-OUP grant-NBT-27-133/2) for this research as well as Universiti Sains Malaysia for the financial support for the first author.

\section{Author's Contributions}

Maizura Murad: Participated in experiments, data analysis and contributed to the writing of the manuscript.

Aminah Abdullah: Conceptualize and design the experiment, interpretation of the data and review and proof-read the manuscript.

Wan Aida Wan Mustapha: Assisted in some data analysis and proof-read the manuscript.

\section{Ethics}

This article is original and contains unpublished material. All of the authors have read and approved the manuscript and no ethical issues involved.

\section{References}

Abdullah, A. and T.C. Cheng, 2001. Optimization of reduced calorie tropical mixed fruit jam. J. Food Quality Preference, 12: 63-68.

DOI: 10.1016/S0950-3293(00)00030-6

Abdullah, A., T.M.M. Malundo, A.V.A. Resurreccion and L.R.I. Beuchat, 1993. Descriptive sensory profiling for optimizing the formula of a peanut milk-based liquid coffee whitener. J. Food Sci., 58: 120-123. DOI: 10.1111/j.1365-2621.1993.tb03224.x

Aminah, A., A.V.A. Resurreccion and L.R. Beuchat, 1993. Formulation and evaluation of peanut milk whipped topping using response surface methodology. LWT-Food Sci. Technol., 26: 162166. DOI: $10.1006 /$ fstl.1993.1033

Annison, G., R.P. Trimble and D.L. Topping, 1995. Feeding Australiana acacia gums and gum Arabic leads to non-starch polysaccharide accumulation in the cecum of rats. J. Nutr., 125: 283-292. PIMD: 7861255
Baeza, R.I., D.J. Carp, O.E. Pe'rez and A.M.R. Pilosof, 2002. K-carrageenan protein interactions: Effect of proteins on polysaccharide gelling and textural properties. LWT-Food Sci. Technol., 35: 741-747. DOI: $10.1006 /$ fstl.2002.0938

Boutboul, A., P. Giampaoli, A. Feigenbaum and V. Ducruet, 2002. Influence of the nature and treatment of starch on aroma retention. Carbohydr. Polym., 47: 73-82. DOI: 10.1016/S0144-8617(01)00160-6

Brannan, R.G., 2009. Effect of grape seed extract on descriptive sensory analysis of ground chicken during refrigerated storage. Meat Sci., 81: 589-595. PMID: 20416587

Cartier, R., A. Rytz, A. Lecomte, F. Poblete and J. Krystlik et al., 2006. Sorting procedure as an alternative to quantitative descriptive analysis to obtain a product sensory map. Food Quality Performance, 17: 562-571.

DOI: $10.1016 /$ j.foodqual.2006.03.020

Castro, I.A., R.S.F. Silva, J. Tirapegui, D. Borsato and E. Bona, 2003. Simultaneous optimization of response variables in protein mixture formulation: Constrained simplex method approach. Int. J. Food Sci. Tech., 38: 103-110. DOI: $10.1046 / j .1365-2621.2003 .00650 . x$

Chang, K.L.B., Y.S. Lin and R.H. Chen, 2003. The effect of chitosan on the gel properties of tofu (soybean curd). J. Food Eng., 57: 315-319. DOI: 10.1016/S0260-8774(02)00345-X

Deshpande, R.P., M.S. Chinnan and K.H. Mcwatters, 2008. Optimization of a chocolate-flavored, peanutsoy beverage using Response Surface Methodology (RSM) as applied to consumer acceptability data. LWT-Food Sci. Technol., 41: 1485-1492. DOI: $10.1016 /$ j.lwt.2007.08.013

Dickinson, E., 2003. Hydrocolloids at interfaces and influence on the properties of dispersed systems. Food Hydrocolloids, 17: 25-39. DOI: $10.1016 / \mathrm{S} 0268-005 \mathrm{X}(01) 00120-5$

Dutcosky, S.D., M. Victoria, E. Grossmann, R.S.S.F. Silva and A.K. Welsch, 2006. Combined sensory optimization of a prebiotic cereal product using multicomponent mixture experiments. J. Food Chem., 98: 630-638.

DOI: $10.1016 /$ j.foodchem.2005.06.029

Gan, H.E., R. Karim, S.K.S. Muhammad, J.A. Bakar and D.M. Hashim et al., 2007. Optimization of the basic formulation of a traditional baked cassava cake using response surface methodology. LWT-Food Sci. Technol., 40: 611-618.

DOI: $10.1016 / j .1 w t .2006 .05 .005$

Gawell, R., A. Oberholster and I.L. Francis, 2000. A "Mouth-feel wheel": Therminology for communicating the mouthfeel characteristics of red wine. Aus. J. Grape Wine Res., 6: 203-207. DOI: $10.1111 /$ j.1755-0238.2000.tb00180.x 
Goycoolea, F.M., E.R. Morris, R.K. Richardson and A.E. Bell, 1995. Solution rheology of mesquite gum in comparison with gum Arabic. Carbohydr. Polym., 27: 37-45.

DOI: $10.1016 / 0144-8617(95) 00031-2$

Kahyaoglu, K., 2008. Optimization of the pistachio nut roasting process using response surface methodology and gene expression programming. LWT-Food Sci. Technol., 41: 26-33. DOI: $10.1016 /$ j.lwt.2007.03.026

Karim, A.A., G.A. Sulebele, M.E. Azhar and C.Y. Ping, 1999. Effect of carrageenan on yield and properties of tofu. J. Food Chem., 66: 159-165. DOI: 10.1016/S0308-8146(98)00258-1

Labbe, M., M. Springett, L.P.B. Wender and P.M. Agerlin, 2006. Off-flavours of soy ingredients: Astringency-sensory perception, key molecules and masking strategies. Dev. Food Sci., 43: 281-284. DOI: $10.1016 / \mathrm{S} 0167-4501(06) 80067-1$

Lesschaeve, I. and A.C. Nobel, 2005. Polyphenols: Factors influencing their sensory properties and their effects on food and beverage preferences. Am. J. Clinical Nutr., 8: 330S-335S. PIMD: 15640499

McWilliams, M., 1997. Starch. In: Food experimental perspectives, McWilliams, M., (Ed.)., Upper Saddle River, New Jersey, ISBN-10: 0135209900, pp: 183-213.

Meilgaard, M.C., G.V. Civille and B.T. Carr, 2006. Sensory Evaluation Techniques. 4th Edn., CRC Press, ISBN-10: 0849338395, pp: 464.

Mirhosseinia, H., C.P. Tan, S.A.N. Hamid and S. Yusof, 2008. Optimization of the contents of Arabic gum, xanthan gum and orange oil affecting turbidity, average particle size, polydispersity index and density in orange beverage emulsion. Food Hydrocolloid, 22: 1212-1223.

DOI: 10.1016/j.foodhyd.2007.06.011
Monaco, R.D., N.A. Miele, S. Cavella and P. Masi, 2010. New chestnut-based chips optimization: Effects of ingredients. LWT-Food Sci. Technol., 43: 126-132. DOI: 10.1016/j.lwt.2009.07.005

Monteleone, E., N. Condelli, C. Dinnella and M. Bertuccioli, 2004. Prediction of perceived astringency induced by phenolic compounds. J. Food Quality Preference, 15: 761-769. DOI: $10.1016 /$ j.foodqual.2004.06.002

Naknean, P. and M. Meenune, 2010. Factors affecting retention and release of flavour compounds in food carbohydrates. J. Int. Food Res., 17: 23-34.

Sajilata, M.G. and R.S. Singhal, 2005. Specialty starches for snack foods. Carbohydr. Polym., 59: 131-151. DOI: 10.1016/j.carbpol.2004.08.012

Terta, M., G. Blekes and A. Paraskevopoulou, 2006. Retention of selected compounds by polysaccharide solution: A Thermodynamic and kinetic approach. J. Food Hydrocolloids, 20: 863871. DOI: 10.1016/j.foodhyd.2005.08.011

Troszynska, A., O. Narolewska, S. Robredo, I. Estrella and T. Hernández et al., 2010. The effect of polysaccharides on the astringency induced by phenolic compounds. J. Food Quality Preference, 21: 463-469.

DOI: $10.1016 /$ j.foodqual.2009.12.005

Venugopal, V., 2008. Marine Products for Healthcare: Functional and Bioactive Nutraceutical Compounds from the Ocean. 1st Edn., CRC Press, ISBN-10: 1420052640, pp: 528.

Yoon, E.K., J.H. Hong, S. Le and K.O. Kim, 2011. Sensory characteristics and consumer acceptability of red ginseng extracts produced with different processing methods. J. Food Sci., 76: S270-S279.

DOI: $10.1111 / \mathrm{j} .1750-3841.2011 .02197 . \mathrm{x}$ 